\title{
Diversity of child health care in Europe
}

Hilary Hoey, ${ }^{1,2}$ Massimo Pettoello-Mantovani, ${ }^{2,3}$ Mehmet Vural (D) 2,4

The health of a nation depends on the health of its children, and it is now evident that child health underpins health in adolescents, later life and also in subsequent generations for a variety of reasons including environmental, metabolic and epigenetic changes. There are many challenges in child health in Europe and globally. ${ }^{12}$ Inequalities in health status and health outcomes of children and adolescents within Europe are of great concern to paediatric societies and all those working in child health. ${ }^{3}$

\section{DIVERSITY A VALUABLE RESOURCE}

Diversity, or noticeable heterogeneity, for many years has generated controversy on whether it is a resource for success or a barrier to improvement. Many feel uncomfortable with the term diversity and some academics and businesses have replaced it with 'inclusion' and 'equity'. Diversity is difficult to interpret in many European contexts, including science and particularly in the care of children, due to differing historical, cultural, social and economic influences. This may lead to misunderstandings, detrimental conflicts, resentment and resistance, so that its benefits are not always realised. However, diversity and inclusion should be perceived as a valuable resource to help provide optimum healthcare for European children living in different social, cultural and economic environments. We should resist the temptation to indiscriminately equalise clinical approaches, but at the same time not compromise therapies, protocols or outcome. We should support countries to provide child health services that best meet the needs of their individual country.

\section{DIVERSITY IN PAEDIATRIC CARE}

European paediatrics has a longstanding history of coping with the concept of diversity. ${ }^{4}$ From the ashes of the two

\footnotetext{
${ }^{1}$ Paediatrics, Trinity College Dublin, Dublin 2, Ireland ${ }^{2}$ European Paediatric Association-Union of National European Paediatric Societies and Associations (EPAUNEPSA), Berlin, Germany

${ }^{3}$ Paediatrics, Ospedale Casa Sollievo della Sofferenza, University of Foggia, San Giovanni Rotondo, Italy ${ }^{4}$ Paediatrics, Istanbul University-Cerrahpasa, Istanbul, Turkey
}

Correspondence to Professor Hilary Hoey, Paediatrics, Trinity College Dublin, Dublin, Ireland; hilaryhoey@gmail.com world wars that engulfed the globe during the past century, Europeans moved to build a better future. Equity and social justice among others were essential factors in this positive effort. Medical science in general and paediatrics in particular experienced an unprecedented boost, favoured by successful scientific cooperation between medical doctors, their institutions and with industrial companies. The multiple achievements reached during this period, such as the development of antibiotics, vaccinations and chemotherapy, well represent that fruitful period. The Cold War and the creation of the iron curtain was an unfortunate obstacle to the integration of European paediatrics into a true single scientific community operating under a common set of principles, promoting the pursuit of knowledge and the sharing of common ethics with regard to the integrity of the scientific process.

In the cultural atmosphere produced by circumstances where scientific interactions between Eastern and Western Europe were extremely rare, European paediatricians felt the compelling need to found in 1975 the Union of National European Paediatric Societies and Associations, later developed into the European Paediatric Association (EPA-UNEPSA). Its mission was to overcome obstacles to productive scientific interactions, embracing diversity as a resource and fostering the exchange of experiences and cooperation among paediatricians in Europe. Its goal was to enable paediatricians and scientific societies exchange scientific information and share best practices, in the spirit of learning across borders and languages. Half a century later and following the collapse of the iron curtain, the importance of exploring diversities and similarities in current challenges and approaches to child health across Europe has not declined. ${ }^{1}$ More recent successful innovations in the prevention and management of healthcare in children include the management of unpredicted challenges such as COVID-19 and fiscal difficulties. ${ }^{5}$ Also, migrant children and adolescents have their own unique health and psychosocial issues requiring additional services and support. ${ }^{6}$ These challenges provide unique opportunities for different countries to share experience.

\section{PAEDIATRIC TRAINING}

There are considerable differences among the 53 European countries in their approach to paediatric educational programmes, curricula content, educational strategies and its quality assurance. Undergraduate paediatric programmes vary from a relatively short period allocated to child health within a general medical curriculum to a curriculum completely devoted to child health.

There are profound diversities among postgraduate paediatric programmes attributable to a multiplicity of factors including history, traditions, model of paediatric care, cultural aspects and economic issues. ${ }^{7}$ Curriculum content varies depending on whether primary care general physicians, primary care paediatricians or combinations of both are primarily responsible for child health. The duration of postgraduate training in general paediatrics varies from 2 to 8 years together with varying assessment procedures. Most countries in Europe need more well-trained general paediatricians and paediatric subspecialists to improve child healthcare.

Continuing professional development and lifelong learning, which is essential for safe patient care, is a mandatory legal requirement in some European countries but not in others.

\section{PAEDIATRICS LOOKING TO THE FUTURE}

Critics of diversity contend that it may only benefit a few privileged countries; however, research indicates that diversity actually benefits everyone. Groups that are not diverse risk being narrow-minded and overlooking important information. Having a variety of perspectives helps new ideas develop as demonstrated by recent research conducted by the European paediatric societies.

During the last two decades, European paediatric research experienced a noteworthy boost, which is documented by the number of scientific articles published on paediatric topics, perinatology and child health. According to the SCImago Journal Rank indicator, the total number of articles published by all European countries in the decade $2008-2019$ increased by $41 \%$ to 115868 , compared with 82045 published in the preceding decade. The countries belonging to the former eastern part of the iron curtain showed an increase in publications from 7141 to 12493 representing a $75 \%$ and an increase from $8.7 \%$ to $10.7 \%$ of the total publications in Europe.

In recent years, changes are more often driven by economic motivations, 
particularly after the 2009 global economic crisis; strategic decisions were taken by governments to reduce budgets allocated to child healthcare due to pressure to deliver more for less, rather than the healthcare needs of children. Social determinants have a major influence on child health and well-being and further research is necessary, including interventional programmes, in order to prevent negative consequences. ${ }^{8}$

The most efficient healthcare approach in paediatrics is based on the harmonisation of primary, secondary and tertiary care in order to provide comprehensive child and adolescent health services. However, many European countries have limited or eliminated primary care paediatrics, with an emphasis on 'balancing the budget', instead of providing good healthcare to children, supported by properly trained professionals. The European Confederation of Primary Care Paediatricians and EPA-UNEPSA have recently joined forces in the shared belief that a coordinated interaction of primary, secondary and tertiary care specialists is essential for the health and well-being of children. These two organisations are collaborating to develop a common strategy to improve child healthcare. Other European Paediatric organisations are welcome to contribute to this common goal and enable European paediatricians to speak with an influential and authoritative voice on behalf of European children and adolescents. ${ }^{1}$

The recent development of electronic platforms greatly enhance the opportunities for collaboration including the collection of extensive local, national and international data along with opportunities for research and quality improvement processes to monitor and improve patient outcomes.

\section{CONCLUSIONS}

Investing in the health and well-being of children is the most effective way to improve adult health and quality of life.
Diversity and inclusion should be the foundation of a prioritised joint effort by European paediatricians and their national organisations to effectively promote the accessibility to optimum healthcare for all children, as well as give protection by ageappropriate laws and regulations.

While each country should have the freedom to adopt and develop variations in child health services, in order to serve the needs of their own community, there is a need for collaboration including the development of standards of training and healthcare across Europe along with monitoring the implementation of policies, provision of services and particularly patient outcomes based on the collection of robust data. ${ }^{9}$

European paediatricians and their professional societies must collaborate and share their experiences with different health challenges and healthcare systems and mitigate against inequalities in child health within and between countries and together strongly and courageously advocate for the health and well-being of children with health service providers and at Government level.

Contributors All three authors (HH, MP-M, MV) contributed to the conception and design of the work, drafting the work and revising it critically for important intellectual content. All three authors approved the submitted version. They also agree to be accountable for all aspects of the work.

Funding The authors have not declared a specific grant for this research from any funding agency in the public, commercial or not-for-profit sectors.

Competing interests None declared.

Patient consent for publication Not required.

Provenance and peer review Commissioned; internally peer reviewed.

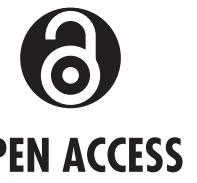

Open access This is an open access article distributed in accordance with the Creative Commons Attribution Non Commercial (CC BY-NC 4.0) license, which permits others to distribute, remix, adapt, build upon this work non-commercially, and license their derivative works on different terms, provided the original work is properly cited, appropriate credit is given, any changes made indicated, and the use is non-commercial. See: http:// creativecommons.org/licenses/by-nc/4.0/.

(C) Author(s) (or their employer(s)) 2021. Re-use permitted under CC BY-NC. No commercial re-use. See rights and permissions. Published by BMJ.

\section{Check for updates}

To cite Hoey H, Pettoello-Mantovani M, Vural M. Arch Dis Child Epub ahead of print: [please include Day Month Year]. doi:10.1136/archdischild-2020-319584

Received 23 May 2020

Revised 8 July 2020

Accepted 15 July 2020

Arch Dis Child 2020;0:1-2.

doi:10.1136/archdischild-2020-319584

\section{ORCID iD}

Mehmet Vural http://orcid.org/0000-0002-3626-0555

\section{REFERENCES}

1 Pettoello-Mantovani M, Mestrovic J, Vural M, et al. Looking at the future, learning from the past: current activities and upcoming goals of the European Paediatric Association, the Union of National European Paediatric Societies and Associations. J Pediatr 2020;220:272-4.

2 Alemán-Díaz AY, Backhaus S, Siebers LL, et al. Child and adolescent health in Europe: monitoring implementation of policies and provision of services. Lancet Child Adolesc Health 2018;2:891-904.

3 Wolfe I, Thompson M, Gill P, et al. Health services for children in Western Europe. Lancet 2013;381:1224-34.

4 Ehrich J, Namazova-Baranova L, PettoelloMantovani M. Introduction to "Diversity of Child Health Care in Europe: A Study of the European Paediatric Association/Union of National European Paediatric Societies and Associations". J Pediatr 2016;177S:S1-10.

5 WHO, EAP, ECPCP, EPA. COVID-19 and breastfeeding position paper, 2020. Available: http://www.euro.who.int

6 Ferrara P, Corsello G, Sbordone A, et al. The "invisible children": uncertain future of unaccompanied minor migrants in Europe. J Pediatr 2016;169:332-3.

7 Meric R, Stone RG, Lupu VV, et al. The diversity of pediatric residency programs across Europe: admission procedures, curricula and duration of courses. J Pediatr 2020;222:266-8.

8 Dharni N, Dickerson J, Willan K, et al. Implementation evaluation of multiple complex early years interventions: an evaluation framework and study protocol. BMJ Paediatr Open 2019;3:e000479.

9 Brenner M, O'Shea MP, McHugh R, et al. Principles for provision of integrated complex care for children across the acute-community interface in Europe. Lancet Child Adolesc Health 2018;2:832-8. 